\title{
Pelatihan Pembuatan Game Edukasi Berbasis Android Berbantuan RPG Maker bagi Siswa SMA Islam Al-Azhar 5 Cirebon
}

\author{
${ }^{1}$ Much. Subali Noto, ${ }^{2}$ Surya Amami Pramuditya, ${ }^{3}$ Setiyani, \\ Universitas Swadaya Gunung Jati, Cirebon \\ 1'msnoto.ugj@gmail.com, 2amamisurya@fkip-unswagati.ac.id, \\ ${ }^{3}$ Setiyani_0401509081@yahoo.com
}

\begin{abstract}
Almost everyone has a smartphone, including students. The potential for open application development on Android and the increasing number of people using smartphones allow them to use technology to support activities in the world of education, one of which is mobile learning. Educational games are a part of mobile learning. The purpose of the Community Service (PKM) activity is to improve students' abilities in utilizing technology through training in Android-based educational games assisted by RPG Maker. Through the making of this educational game, students can develop an interest in IT and learn mathematics. Participants in the PKM activities were students of Al-Azhar 5 Islamic High School Cirebon City who became the KIR community members. This service method consisted of three stages, namely preparation, implementation of training, and evaluation. The indicators of this activity's achievement include students being able to make maps, prologues, bring up avatars, create questions, create dialogues, battle, move one character from one map to another, and deploy games successfully controlled by participants. During the training, the participants were very enthusiastic in listening to the material and were active in making educational games.
\end{abstract}

Keywords: Educational Game; Training; RPG Maker

\begin{abstract}
Abstrak
Hampir setiap orang memiliki smartphone termasuk pelajar. Potensi pengembangan aplikasi yang terbuka pada Android dan semakin banyaknya masyarakat yang menggunakan smartphone, membuka peluang teknologi ini dapat digunakan untuk mendukung aktivitas dalam dunia pendidikan salah satunya adalah mobile learning. Game edukasi merupakan salah satu bagian dari mobile learning. Tujuan dari kegiatan Pengabdian Kepada Masyarat (PKM) adalah untuk meningkatkan kemampuan siswa dalam memanfaatkan teknologi melalui pelatihan game edukasi berbasis Android berbantuan RPG Maker. Melalui pembuatan game edukasi ini, siswa dapat mengembangkan minat di bidang IT sekaligus belajar matematika. Peserta dalam kegiatan PKM adalah siswa SMA Islam Al-Azhar 5 Kota Cirebon yang tergabung dalam komunitas KIR. Metode dalam pengabdian ini terdiri dari tiga tahap yaitu persiapan, pelaksanaan pelatihan, dan evaluasi. Indikator
\end{abstract}


ketercapaian kegiatan ini diantaranya siswa mampu membuat map, prolog, memunculkan avatar, membuat soal, membuat dialog, battle, memindahkan satu tokoh dari map satu ke map yang lain, serta mendeploy game berhasil dikuasai oleh peserta. Selama pelatihan berlangsung, peserta sangat antusias dalam menyimak materi dan aktif dalam pembuatan game edukasi.

Kata Kunci: Game Edukasi, Pelatihan, RPG Maker

\section{Pendahuluan}

Pada era globalisasi ini banyak siswa yang sudah memanfaatkan teknologi untuk menyelesaikan permasalahan matematika. Tidak sedikit juga dari mereka yang mulai memanfaatkan teknologi sebagai sumber belajar. Sehingga teknologi yang kian lama kian canggih ini dapat membantu siswa dalam pembelajaran matematika. Beberapa contoh teknologi yang digunakan yaitu: PC (Personal Computer), Laptop, smartphone, internet, dan lain-lain. Matematika merupakan salah satu materi pembelajaran yang memiliki objek yang abstrak. Untuk memudahkan dalam memahami materi yang abstrak kita harus membuatnya dalam bentuk yang kongkrit dan dengan teknologi saat ini yang semakin canggih dapat memudahkan kita untuk membuat materi yang abstrak menjadi lebih kongkrit. Selain itu juga pada saat ini mulai banyak pendidik yang menciptakan game sebagai sarana sumber belajar.

Menurut Novaliendry (2013), game edukasi adalah permainan yang telah dirancang khusus untuk mengajarkan siswa (user) suatu pembelajaran tertentu, pengembangan konsep dan pemahaman dan membimbing mereka dalam melatih kemampuan mereka, serta memotivasi mereka untuk memainkannya. Sedangkan menurut Widiastuti dan Setiawan, (2013) game edukasi adalah game digital yang dirancang untuk pengayaan pendidikan (mendukung pengajaran dan pembelajaran), menggunakan teknologi multimedia interatif.

Menurut Hurd dan Jenuings (dalam Widiastuti \& Setiawan, 2013), perancang yang baik haruslah memenuhi kriteria dari education game itu sendiri. Berikut ini adalah beberapa kriteria dari sebuah education game, yaitu: nilai keseluruhan (overall value), dapat digunakan (usability), keakuratan (accuracy), kesesuaian (appropriateness), relevan (relevance), objektifitas (objectives), umpan balik (feedback). Adapun dampak positif yang dihasilkan oleh game edukasi diantaranya dengan memainkan game membuat anak mengenal teknologi komputer, Game dapat memberikan pelajaran dalam hal mengikuti pengajaran dan aturan, beberapa game menyediakan latihan untuk pemecahan masalah dan logika.

Beberapa penelitian telah dilakukan terkait game edukasi berbasis Android pada semua tingkat sekolah, diantaranya: penelitian (Yunus, Astuti, \& Khairina, 2015) yang diujikan kepada guru, siswa SD dan beberapa gamers, diperoleh kesimpulan bahwa game dapat dijadikan sumber belajar dan merupakan inovasi dalam media pembelajaran. Penelitian terkait game 
edukasi matematika pada tingkat SMP dan SMA juga telah dilakukan (Pramuditya, Noto, \& Syaefullah, 2017; S. A. Pramuditya, Noto, \& Purwono, 2018; S. Pramuditya, Noto, \& Syaefullah, 2018), hasil menunjukan bahwa game dapat meningkatkan kemampuan matematis siswa. Menurut Kristanti (2014), media pembelajaran dapat meningkatkan hasil belajar siswa sebesar $14,48 \%$ dan meningkatkan kualitas proses belajar yang ditunjukan dengan peningkatan minat sebesar $13,45 \%$. Menurut penelitian Narmada, Darmawiguna, \& Sunarya (2015) berdasarkan uji responden Game Edukasi Tradisional Pupuh berbasis Android, yang dilakukan dengan melibatkan siswa SMP dan SMA, hasil menunjukan respons sebesar $81,9 \%$ berarti hasil uji respons baik.

Berdasarkan hasil-hasil positif dari beberapa pengabdian dalam mengembangkan profesionalisme guru dalam menghadapi era digital, penulis merasa alangkah baiknya jika pelatihan mengenai cara pembuatan game edukasi matematika dengan RPG dilakukan di beberapa sekolah. Hal ini memberi peluang besar untuk siswa dalam mengembangkan bakat dan minatnya dibidang IT.

SMA Islam Al - Azhar 5 Cirebon adalah salah satu sekolah swasta terbaik di Kota Cirebon. Namun sayangnya, pemanfaatan IT belum dilakukan maksimal. Tim mendapat infomasi bahwa belum pernah ada pelatihan mengenai cara membuat game edukasi matematika berbasis Android pada sekolah tersebut. Padahal SMA Islam Al-Azhar 5 memiliki fasilitas lengkap seperti lab komputer. Guru-guru di sekolah tersebut sudah terbiasa mengajar menggunakan bantuan informasi dan teknologi. Berdasarkan penelitian diatas bahwa Game edukasi berbasis Android merupakan inovasi dalam pembuatan media pembelajaran yang dapat meningkatkan hasil belajar dan kualitas proses belajar yang ditunjukan dengan peningkatan minat terhadap suatu materi. Berdasarkan analisis situasi dan kebutuhan akan pentingnya membuat game edukasi matematika berbasis Android, tim tertarik melakukan kegiatan Pengabdian Kepada Masyarakat (PKM) dengan tema Pelatihan Pembuatan Game Edukasi Matematika Berbasis Android Bagi Siswa SMA Islam Al-Azhar 5 Kota Cirebon.

\section{Metode}

Membuat game edukasi berbasis Android menggunakan RPG maker adalah tujuan dari pengabdian terhadap masyarakat ini. Peserta yang mengikuti kegiatan PKM adalah siswa SMA Al-Azhar 5 yang memiliki minat pada IT. Mereka tergabung dalam komunitas KIR. Situasi pandemi yang menetapkan kota Cirebon ke dalam zona merah, membuat peserta yang berpartisipasi dibatasi yaitu sebanyak 4 orang. Kegitan PKM melibatkan 2 orang mahasiswa sebagai narasumber dan 2 orang dosen sebagai observer. Metode pengabdian ini terdiri dari 3 tahap yaitu tahap persiapan, pelaksanaan pelatihan, dan evaluasi. Adapun deskripsi setiap tahapan PKM sebagai berikut. 


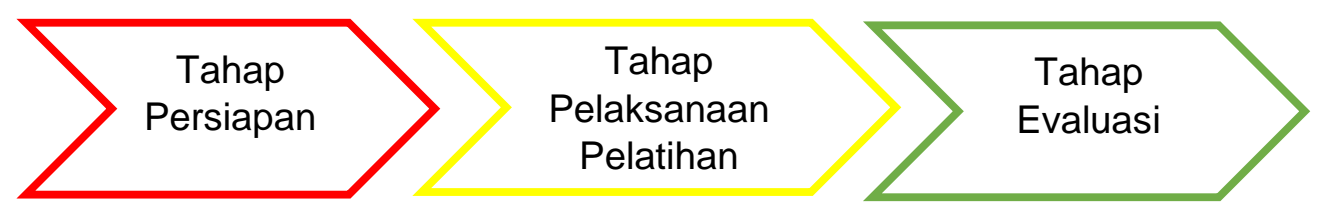

Gambar 1. Metode Pengabdian

\section{a. Tahap Persiapan}

Pada tahap persiapan kegiatan yang dilakukan adalah survey kebutuhan siswa, pemantapan dan penetuan lokasi dan sasaran, penyusunan bahan/materi pelatihan, yang meliputi: makalah dan modul untuk kegiatan pelatihan pembuatan game edukasi berbasis Android bagi guru dan siswa.

\section{b. Tahap Pelaksanaan Pelatihan}

Dalam tahap ini yang dilakukan pertama, penjelasan tentang pentingnya penggunaan software RPG, sesi pelatihan ini menitikberatkan pada pemberian penjelasan mengenai pentingnya merubah gaya belajar yang konvensional menjadi pembelajaran berbasis IT yang lebih interaktif; kedua, sesi pelatihan yang menitikberatkan pada kemampuan melaksanakan kegiatan tentang melakukan instalasi RPG, mengeksplorasi dan menggunakan menu dan tool RPG, menambahkan dan memasukan animasi pada game edukasi, membuat soal latihan interaktif. Pemberian kemampuan ini dilakukan dengan teknik simulasi agar peserta mendapatkan pengalaman langsung sekaligus pengayaan dari tim.

\section{c. Tahap Evaluasi}

Setelah sesi pelatihan, selanjutnya peserta diminta menuliskan tanggapan berupa pesan dan kesan pelatihan ini dengan mengisi angket yang telah disediakan. Tujuannya adalah untuk mengetahui kebermanfaatan pelatihan pembuatan game edukasi berbasis Android ini dan mengantisipasi kekurangan yang terjadi pada pelatihan serupa selanjutnya.

\section{Hasil dan Pembahasan}

Pelatihan pembuatan game edukasi berbasis Android menggunakan software RPG Maker dilaksanakan pada tanggal 21 September 2020 bertempat di ruang kelas SMA Islam Al-Azhar 5 Kota Cirebon. Berdasarkan tahapan kegiatan yang telah diuraikan pada metode pelatihan, setelah tahap persiapan maka tahap selanjutnya adalah peserta mengikuti tahap pelatihan. Peserta yang mengikuti kegiatan pelatihan ini sebanyak 4 orang siswa yang tergabung dalam komunitas KIR. Pada awal pelatihan tim memberikan game engine untuk dilakukan instalasi pada laptop peserta. Setelah itu, tim melakukan demonstrasi cara membuat game yang kemudian diikuti oleh masing-masing peserta. Adapun tahapan pemaparan materi PKM sebagai berikut.

\section{a. Membuat Map pada Tampilan Awal}

Pemilihan map sudah tersedia pada RPG maker, tim meminta peserta untuk mencoba-coba map dan memilih sesuai dengan keinginan. Apabila 
map tidak ada yang cocok atau tidak sesuai story board, maka untuk membuat map bisa menggunakan software adobe photosop. Adapun aktivitas peserta dalam membuat map dapat dilihat pada gambar 2 .

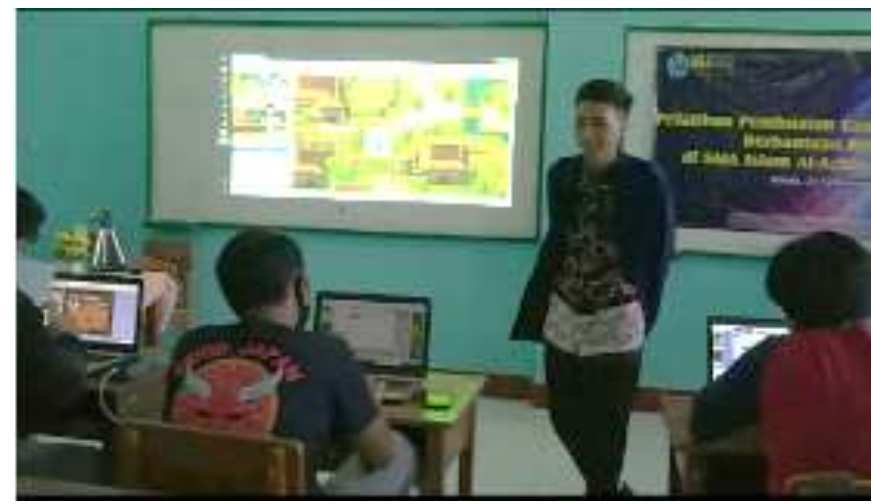

Gambar 2. Pembuatan Map

\section{b. Membuat Prolog}

Prolog disini berisikan mengenai pengenalan game dan petunjukpetunjuk yang di berikan guna memperlancar jalannya game agar bisa dimainkan sampai game selesai. Adapun aktivitas peserta dalam membuat prolog dapat dilihat pada gambar 3.

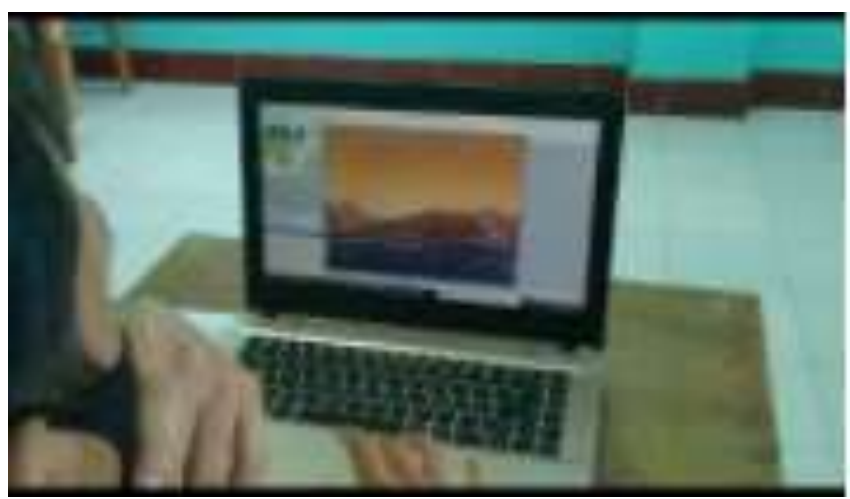

Gambar 3. Pembuatan Prolog

\section{c. Memunculkan Avatar}

Karakter/tokoh yang akan digunakan pada game bisa didesain sendiri sesuai keinginan pembuat game, Caranya yaitu klik Character Generator pada toolbar, Character Generator digunakan untuk membuat desain karakter/tokoh baik pemilihan gender, warna kulit, wajah, rambut dan lainnya sesuai keinginan kita. Adapun aktivitas peserta dalam membuat avatar pada game dapat dilihat pada gambar 4 . 


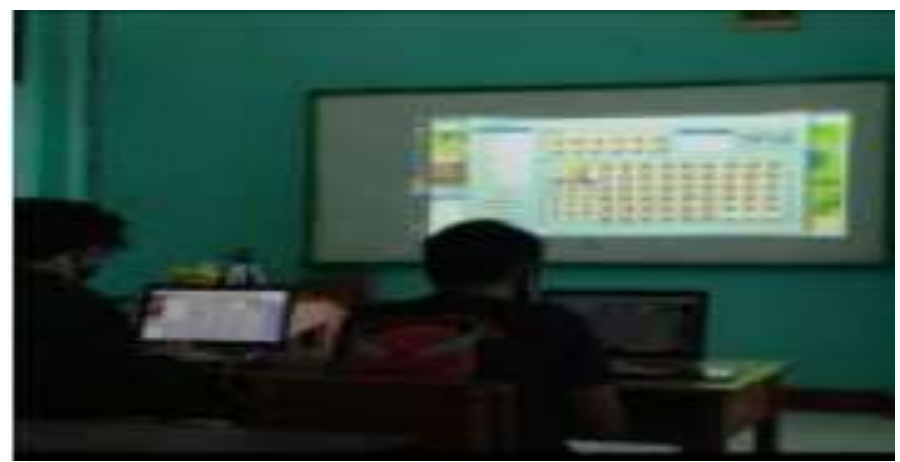

Gambar 4. Avatar

\section{d. Membuat Soal}

Pada game ini terdapat banyak sekali tokoh yang harus ditemui oleh tokoh utama, karena setiap tokoh yang ditemui akan ada informasi baru berupa materi serta pertanyaan-pertanyaan yang memiliki nilai edukasi matematika didalamnya. Adapun aktivitas peserta dalam membuat soal pada game dapat dilihat pada gambar 5 .

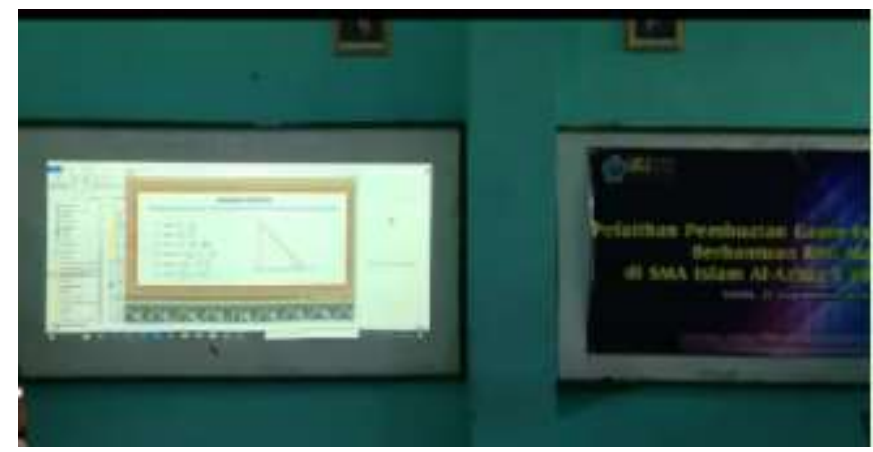

Gambar 5. Membuat Soal

\section{e. Membuat Dialog Antar Tokoh}

Menampilkan percakapan antar tokoh pada dasarnya sama dengan menampilkan teks prolog, yang membedakan adalah pada tampilan Dialog Event Editor. Dimana pada kolom Image masukan tokoh untuk lawan bicara, pada kolom Option beri centang pada Walking agar tokoh tersebut berpindah posisi dengan cara berjalan, pada kolom Autonomous Movement pilih Custom lalu klik Route pada menu Type untuk mengatur pergerakan tokoh tersebut sesuai keinginan kita, terakhir pada menu Trigger pilih Player Touch agar tokoh tersebut berbicara hanya jika menemuinya. Adapun aktivitas peserta dalam membuat dialog antar tokoh pada game dapat dilihat pada gambar 6 . 


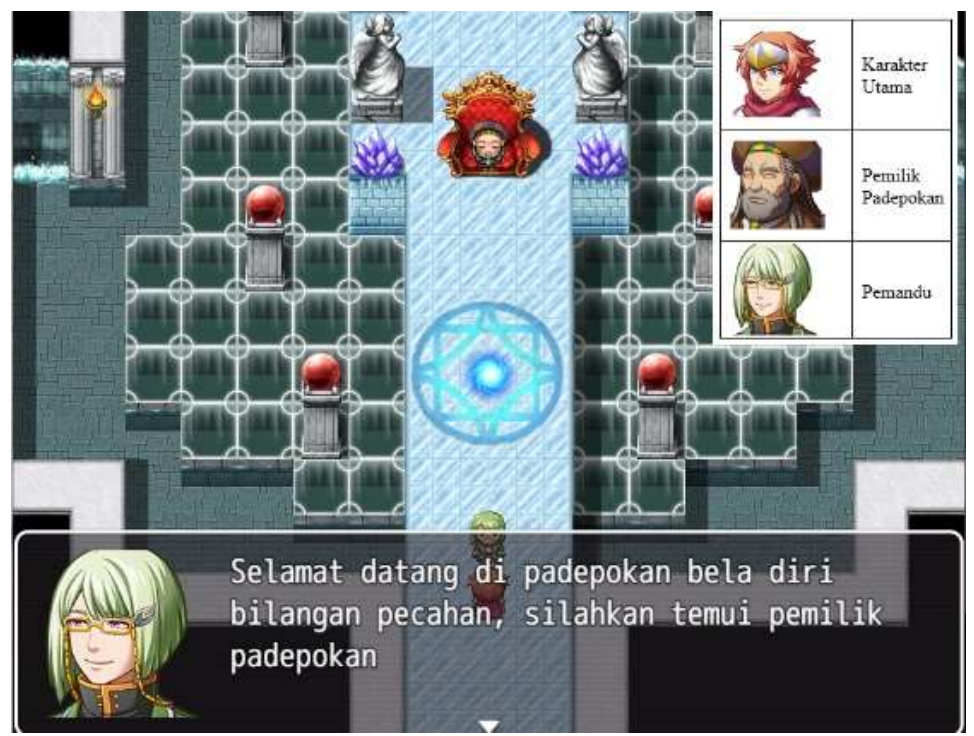

Gambar 6. Membuat dialog antar tokoh

\section{f. Menampilkan Battle}

Battle processing digunakan untuk menampilkan battle dalam game. Pada tampilan dialog battle Processing, kita bisa memilih monster yang ingin ditampilkan pada game dikolom Troop. Setelah memilih monster lalu klik OK. Adapun aktivitas peserta dalam menampilkan battle dapat dilihat pada gambar 7.

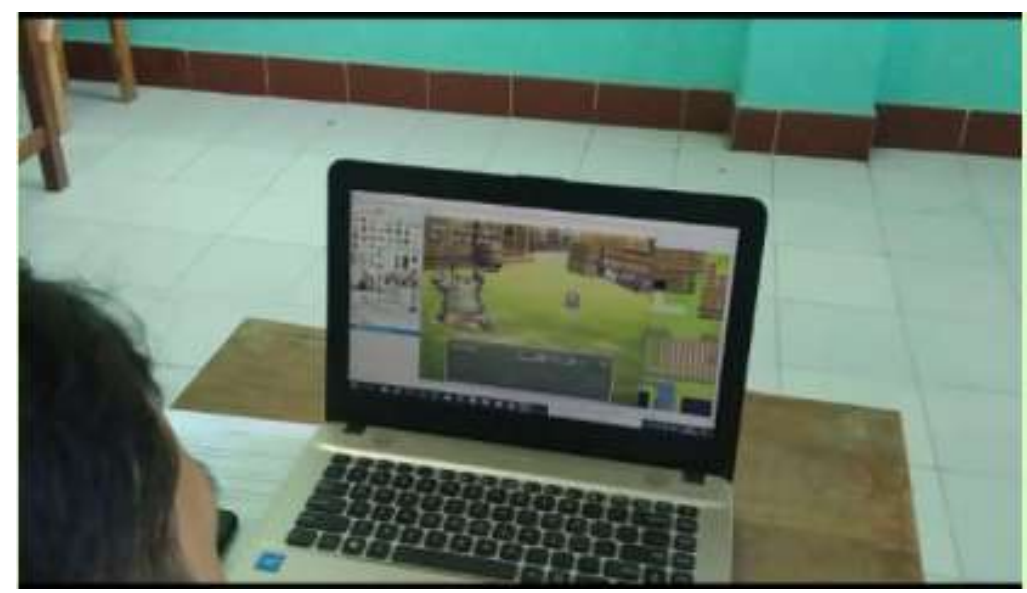

Gambar 7. Menampilkan Battle

\section{g. Memindahkan Tokoh dari Satu Tempat ke Tempat Lain}

Pemindahan tokoh dari satu map ke map yang lain sangat penting untuk mendukung jalan nya cerita. Aktivitas peserta dalam memindahkan tokoh dari satu map ke map yang lain dapat dilihat pada gambar 8 . 

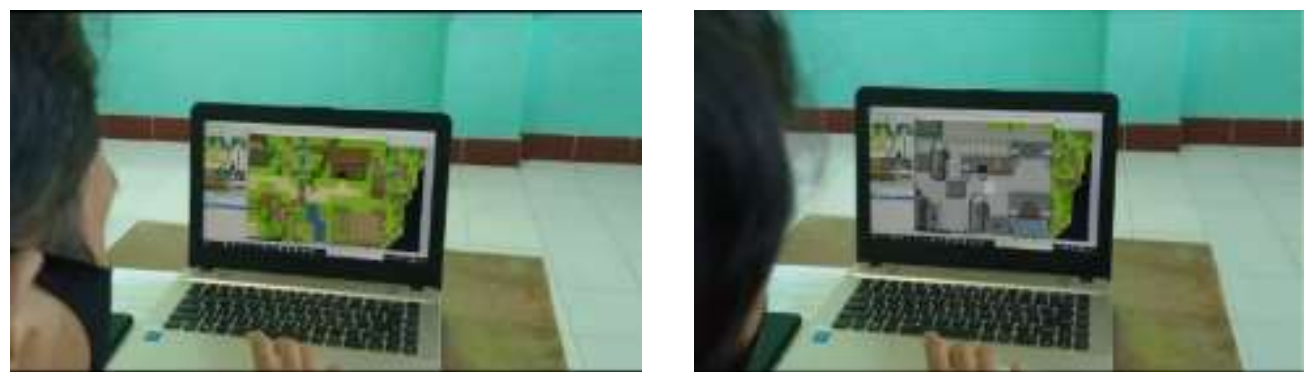

Gambar 8. Perpindahan Map

\section{h. Menampilkan Soal Berupa Pilihan Ganda}

Untuk menampilkan soal pilihan ganda digunakan show choices. Langkah-langkahnya sebagai berikut. Pertama doubleklik pada kolom Contents maka akan tampil bentuk dialog Event Commands, kemudian pilih Show Choices. Aktivitas peserta dalam menampilkan soal berupa pilihan ganda dapat dilihat pada gambar 9

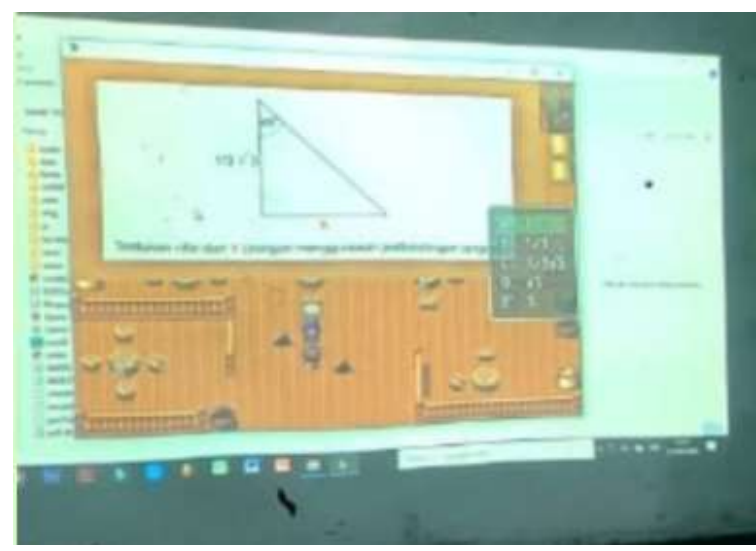

Gambar 9. Pembuatan Soal Pilihan Ganda

\section{i. Mendeploy Game}

Setelah game selesai dibuat, hal yang dilakukan selanjutnya adalah mendeploy game tersebut agar bisa dimainkan baik di PC/laptop ataupun di smartphone Android. Aktivitas peserta dalam menampilkan soal berupa pilihan ganda dapat dilihat pada gambar 10 .

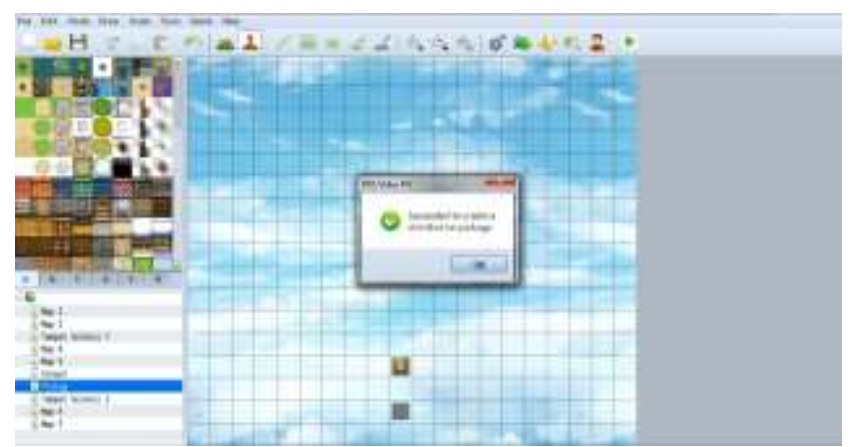

Gambar 10. Mendeploy game 
Selama pelaksanaan pelatihan pembuatan game edukasi berbasis Android menggunakan software RPG Maker, dua orang dosen mengamati aktivitas setiap peserta. Adapun hasil rekapitulasi lembar observasi peserta dapat dilihat pada tabel 1 berikut.

Tabel 1. Rekapitulasi Lembar Observasi

\begin{tabular}{lc}
\hline \multicolumn{1}{c}{ Kriteria } & Terlaksana \\
\hline Kemampuan siswa dalam membuat map pada tampilan & $100 \%$ \\
Kawal & $93.75 \%$ \\
Kemampuan siswa dalam membuat prolog/pembuka & $93.75 \%$ \\
sesuai dengan story board. & $100 \%$ \\
Kemampuan siswa memunculkan avatar & $100 \%$ \\
Kemampuan siswa membuat soal pada RPG & $100 \%$ \\
Kemampuan siswa membuat dialog antar tokoh & $100 \%$ \\
game. & $100 \%$ \\
Kemampuan siswa dalam menampilkan Battle di dalam & \\
satu tempat ke tempat lain. & $100 \%$ \\
Kemampuan siswa dalam menampilihan soan ganda & \\
Kemampuan siswa dalam mendeploy game & \\
\hline
\end{tabular}

Berdasarkan hasil rekapitulasi lembar observasi pada tabel 1, rata-rata aktivitas peserta sebesar $98.6 \%$ termasuk kriteria sangat baik. Seluruh peserta terlibat penuh selama kegiatan PKM. Peserta juga aktif terlibat dalam diskusi dan pada sesi terakhir salah satu peserta mempresentasikan hasil pembuatan game nya.

Sebagai luaran tambahan, tim PKM melibatkan media massa yaitu koran radar Cirebon yang meliput kegiatan ini. Berita PKM yang telah dilakukan terbit pada hari Rabu, 23 September 2020. Adapun dokumentasi koran dapat dilihat pada gambar 11 .

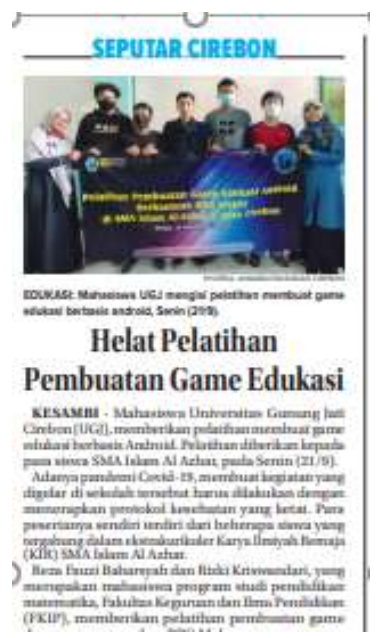

Gambar 10. Berita PKM di Koran Radar Cirebon 


\section{Kesimpulan}

Kegiatan PKM pelatihan pembuatan game edukasi berbasis Android menggunakan Software RPG Maker bagi siswa SMA Islam Al-Azhar 5 berjalan lancar sesuai dengan rencana. Indikator ketercapaian kegiatan ini diantaranya siswa mampu membuat map, prolog, memunculkan avatar, membuat soal, membuat dialog, battle, memindahkan satu tokoh dari map satu ke map yang lain, serta mendeploy game berhasil dikuasai oleh peserta. Kegiatan PKM ini menjadi stimulus bagi siswa untuk tetap mengekspolarasi diri agar terus menghasilkan karya-karya terbaik terutama di bidang IT.

\section{Ucapan Terimakasih}

Tim PKM mengucapkan terimakasih kepada Lembaga Pengabdian Masyarakat (LPM) Univeritas Swadaya Gunung Jati yang telah memberikan hibah dengan nomor kontrak 02/LPM-UGJ/VII/2020.

\section{Daftar Pustaka}

Kristanti, D. (2014). Upaya Meningkatkan Prestasi Belajar Matematika Materi Bangun Datar melalui Media Tangram pada Siswakelas VII SMP Negeri 25 Surabaya. Jurnal Pendidikan Kota Surabaya, 4, 1-12.

Narmada, I. N., Darmawiguna, I. G. M., \& Sunarya, I. M. G. (2015). Pengembangan Game Edukasi Tradisional Pupuh Berbasis Android. KARMAPATI (Kumpulan Artikel Mahasiswa Pendidikan Teknik Informatika), 4(5), 508-516. doi: 10.23887/karmapati.v4i5.6622

Novaliendry, D. (2013). Aplikasi Game Geografi Berbasis Multimedia Interaktif (Studi Kasus Siswa Kelas IX SMPN 1 Rao). Jurnal Teknologi Informasi \& Pendidikan, 6(2), 106-118.

Pramuditya, S. A., Noto, M. S., \& Purwono, H. (2018). Desain Game Edukasi Berbasis Android pada Materi Logika Matematika. JNPM (Jurnal Nasional Pendidikan Matematika), 2(2), 165-179. doi: 10.33603/jnpm.v2i2.919

Pramuditya, S. A., Noto, M. S., \& Syaefullah, D. (2017). Game Edukasi RPG Matematika. Eduma: Mathematics Education Learning and Teaching, 6(1), 77-84. doi: 10.24235/eduma.v6i1.1701

Pramuditya, S., Noto, M., \& Syaefullah, D. (2018). The Educational Game Design on Relation and Functionmaterials. Journal of Physics: Conference Series, 1013(1), 1-8. doi: 10.1088/1742$6596 / 1013 / 1 / 012138$

Widiastuti, N. I., \& Setiawan, I. (2013). Membangun Game Edukasi Sejarah Walisongo. Komputa: Jurnal IImiah Komputer Dan Informatika, 1(2), 18.

Yunus, M., Astuti, I. F., \& Khairina, D. M. (2015). Game Edukasi Matematika Untuk Sekolah Dasar. Informatika Mulawarman: Jurnal IImiah IImu Komputer, 10(2), 59-64. doi: 10.30872/jim.v10i2.192 